\title{
Cloning, Expression, Purification, and Characterization of Clostridium botulinum Neurotoxin Serotype F Domains
}

\author{
Santosh Dulal ${ }^{{ }^{*}}$, Bhupal Ban ${ }^{2}$, Gi Hyoek Yang ${ }^{2}$, and Hyun Ho Jung ${ }^{1,2}$ \\ ${ }^{1}$ Department of Applied Molecular Biology, Sun Moon University, Asan-si, Chung-nam, 336-708, The Republic of Korea \\ ${ }^{2}$ Medy-Tox Inc., Cheongwon-gun, Chungbuk-do, 363-883, The Republic of Korea \\ *Correspondence Author recent address: Microbiology Graduate Program, Department of Biology, New Mexico State \\ University, Las Cruces, NM 88003, United States of America. \\ E-mail: santoshd@nmsu.edu
}

\begin{abstract}
The use of recombinant BoNT domains has been proposed as a means to develop strategies to treat and prevent botulism. Here, details on the molecular cloning, protein expression, purification, and immunoreactivity of BoNT/F domains from Clostridium botulinum are presented. Initially, fulllength synthetic genes encoding recombinant BoNT/F domains (catalytic, translocation, and receptor binding) were designed and cloned into Escherichia coli for expression. Recombinant proteins were then purified through GST affinity chromatography preceding elution of GST-free recombinant domains by thrombin protease. Soluble recombinant proteins encoding catalytic light chain and translocation N-terminal heavy chain were subsequently used to perform in vivo immunization. Polyclonal mouse antibodies specific to these domains were raised, confirmed by Western blot analysis and elevated immunoreactivity was identified through indirect ELISA. In conclusion, availability of the recombinant protein provides an effective system to study the immunological aspects of BoNT/F and corresponding applications in pathogen detection and vaccine candidacy.
\end{abstract}

Keywords: Clostridium botulunium; Botulinum Neurotoxin Type F (BoNT/F) domains; cloning; recombinant protein expression; immunoreactivity

\section{Introduction}

Botulinum neurotoxins (BoNTs), the most potent of all biological substances known to date, are produced by several species of the genera Clostridia (C. botulinum, C. butyricum, and C. baratii) [1-3]. Seven immunologically distinct botulinum neurotoxin serotypes BoNTs/A-G are produced and implicated in botulism poisoning [4]. Botulism is a serious neuroparalytic disease [5], which generally occurs through ingestion of preformed toxin or rarely, through infection of wounds. The Center for Disease Control and Prevention (CDC) classifies BoNTs, among the six highest risk threat agents for bioterrorism "class A biological warfare agent" [6, 7]. Despite their potential to be used for deleterious purposes, BoNTs have increasing 
applications in cosmetics [8] and therapeutics for the treatment of numerous dystonias, inflammation, and chronic pain [9-11].

Botulinum neurotoxin serotype $\mathrm{F}(\mathrm{BoNT} / \mathrm{F})$, is a member of the botulinum neurotoxin family as a single $\sim 150 \mathrm{kDa}$ inactive polypeptide chain post-translationally nicked, forming a dichain consisting of a C-terminal $\sim 100 \mathrm{kDa}$ heavy chain $(\mathrm{HC})$ and a $\mathrm{N}$-terminal $\sim 50 \mathrm{kDa}$ light chain (LC) linked by a disulphide bond $[12,13]$. BoNT/F cleaves its substrate vesicle associated membrane protein (VAMP) at position $\left(\mathrm{Gln}^{58}\right.$-Lys $\left.{ }^{59}\right)$ [14, 15], one of three neuronal proteins associated with exocytosis; subsequently inhibiting acetylcholine release, resulting in death by flaccid paralysis $[16,17]$. Each BoNT/F partial fragment; light chain catalytic domain (rF-LC), N-terminal half of the heavy chain translocation domain $(\mathrm{rF}-$ $\mathrm{HN}$ ), the C-terminal half of the heavy chain receptor binding domain $(\mathrm{rF}-\mathrm{HC})$, and $\mathrm{C}$ terminal quarter part of the heavy chain receptor binding domain $(\mathrm{rF}-\mathrm{HCc})$ plays a specific role in the toxicity mechanism [18, 19]. Botulinum neurotoxin LCs operate by zinc dependent proteolysis involved in neurotransmitter exocytosis from presynaptic termini [20]. Botulinum neurotoxin $\mathrm{HNs}$ possesses channel-forming capability in the acidic environment of the endosome, allowing internalization of the toxin, while HCs are involved in specific binding to the presynaptic membrane via gangliosides and a protein co- receptor [21]. Lastly, the $\mathrm{HCc}$ region of BoNTs are known to harbor the receptor binding neutralizing epitopes which are targets for antibodies that can specifically bind to the receptor, and show neutralizing activity against BoNT toxicity [22].

Thus, it is imperative to construct each domain for the analysis of their molecular and biochemical activities as well as for the development of potential neutralizing antibodies specific to each. To achieve this goal, BoNT/F domains from $C$. botulinum were cloned and expressed using a high expression vector and compatible host E. coli strains to obtain high quality of recombinant proteins suitable for administration into mice.

\section{Methods}

\section{Chemicals, Buffers, and Reagents}

Components related to DNA manipulation, including Ex-Taq polymerase, dNTP, and restriction enzymes were purchased from Takara Bio. Inc., (Shiga, Japan). Luria Bertani (LB) media and cell culture media were purchased from Becton Dickinson and Company (MD, USA) and Hyclone (UT, USA) respectively. Additional chemicals including ampicillin, IPTG, Freund's complete and incomplete adjuvant, and buffers were purchased from Sigma Aldrich (MO, USA).

\section{Bacterial strains, plasmids, and purification}




\section{systems}

C. botulinum type F strain Langeland [23] and BoNT/F (Wako Pure Chemicals Ind., Osaka, Japan) was kindly supplied by Medy-Tox Inc. Plasmids pGEX-4T-1 (Amersham Pharmacia Biotech acquired by GE Healthcare, Uppsala, Sweden) and pET-32a(+) (Novagen, EMD Chemicals Inc., affiliate of Merck $\mathrm{KGaA}$, Darmstadt, Germany) were used for the construction of expression vectors. E. coli strains DH5 $\alpha$ (Takara Bio Inc.), BL21CodonPlus-RIL and BL21-CodonPlus(DE3)RIL (Stratagene, CA, USA) were used as host strains for propagation and expression of recombinant proteins, respectively. Glutathione-S-Transferase (GST) purification modules and thrombin protease were purchased from Amersham Pharmacia Biotech.

\section{Construction of BoNT/F domains}

Chromosomal DNA was isolated from $C$. botulinum F str. Langeland, which was used as the template for polymerase chain reaction (PCR) for all domains (Fig. 1). Forward and reverse primers for each domain were designed (Table 1) based on the published NCBI sequence of the Langeland genome (NC_009699).

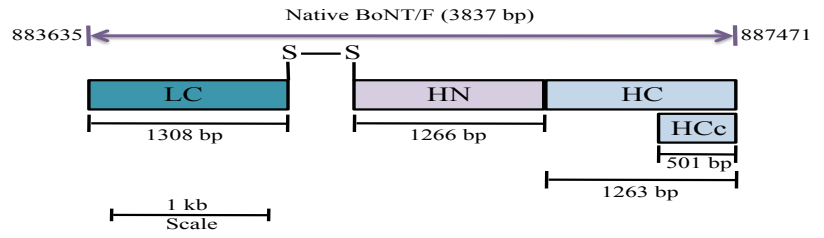

Fig.1: Schematic diagram demonstrating BoNT/F domains for cloning.
Synthetic genes encoding BoNT/F LC (light chain), catalytic domain (1308 bp); HN (N-terminal $1 / 2$ of heavy chain), translocation domain (1266 bp); HC (C-terminal 1/2 of heavy chain), receptor binding domain (1263 bp); and HCc (far Cterminal quarter part of heavy chain), (501 bp) were designed based on the published BoNT/F sequence (ORF: 883635-887471) Langeland str. (NCBI GenBank Accession: NC_009699) for the plasmid construction of each domain.

bp indicates base pair of DNA.

$1 \mathrm{~kb}$ marker is provided for scale.

TABLE 1. Primers used for amplification of BoNT/F domains.

\begin{tabular}{|c|c|c|c|}
\hline $\begin{array}{l}\text { Primer" } \\
\end{array}$ & Sequence $5^{\prime} \rightarrow 3^{\text {th }}$ & Nucleotide positions ${ }^{c}$ & Restriction enzymes $^{d}$ \\
\hline $\begin{array}{l}\text { F-LC-F } \\
\text { F-LC-R }\end{array}$ & $\begin{array}{l}\text { CGTGTCGACATGCCAGTTGTAATAAATAGTTTT } \\
\text { CCGGCGGCCGCTTATTTTCTAGGAATAACGCTCTT }\end{array}$ & $\begin{array}{l}883635-883658 \\
884942-884922\end{array}$ & $\begin{array}{l}\text { Salt } \\
\text { Not1 }\end{array}$ \\
\hline $\begin{array}{l}\text { F-HN-F } \\
\text { F-HN-R }\end{array}$ & $\begin{array}{l}\text { CGTGGATCCGGTACAAAGGCGCCACCGCGACTA } \\
\text { CCGCTCGAGTIAATATAAAATTAGAATTTATC }\end{array}$ & $\begin{array}{l}884943-884966 \\
886209-886188\end{array}$ & $\begin{array}{l}\text { Bam } \mathrm{HI} \\
\text { Xhol }\end{array}$ \\
\hline $\begin{array}{l}\text { F-HC-F } \\
\text { F-HC-R }\end{array}$ & $\begin{array}{l}\text { CGTGGATCCTTTAATAAATTATATAAAAAAATT } \\
\text { CCGCTCGAGTTAGTTTTCTTGCCATCCATGCTC }\end{array}$ & $\begin{array}{l}886209-886232 \\
887471-887448\end{array}$ & $\begin{array}{l}\text { Bam } \mathrm{HI} \\
\text { Xhol }\end{array}$ \\
\hline $\begin{array}{l}\mathrm{F}-\mathrm{HCc}-\mathrm{F} \\
\mathrm{F}-\mathrm{HCc}-\mathrm{R}\end{array}$ & $\begin{array}{l}\text { CGTGGATCCGATAAGTCTATTACTCAGAATTCA } \\
\text { CCGCTCGAGITAGTTTTCTTGCCATCCATGCTC }\end{array}$ & $\begin{array}{l}886971-886994 \\
887471-887448\end{array}$ & $\begin{array}{l}\text { Bam } \mathrm{HI} \\
\text { Xhol }\end{array}$ \\
\hline
\end{tabular}

${ }^{\mathrm{a}}$ Primer direction: $\mathrm{F}$, forward; R, reverse.

${ }^{b}$ Direction of each sequence is in 5 ' to $3{ }^{\prime}$ orientation (underlined) including restriction endonuclease sequence (bold) and inserted stop codon sequences (blue) for $\mathrm{LC}$ and $\mathrm{HN}$ reverse primers.

cNucleotide positions based on published $C$. botulinum $\mathrm{F}$ str. Langeland genome sequence (NCBI Genbank accession: NC_009699).

${ }^{\mathrm{d}}$ Restriction endonucleases utilized to digest PCR amplified domain and vector for plasmid construction.

Isolation of genomic DNA was done utilizing protocols and chemicals mentioned by Wizard Genomic DNA Purification Kit (Promega, WI, USA). PCR was performed using a Bio-Rad iCycler (CA, USA). Reaction mixtures were preheated for $5 \mathrm{~min}$ at $94{ }^{\circ} \mathrm{C}$ for initial denaturation and then 30 cycles of PCR (denaturation, annealing, and elongation) were performed for amplification of domains as follows: $1 \mathrm{~min}$ at $94{ }^{\circ} \mathrm{C}, 1 \mathrm{~min}$ at $57^{\circ} \mathrm{C}$, and 1 $\min 30 \mathrm{sec}$ at $72{ }^{\circ} \mathrm{C}$ for F-LC; 1 min at $94{ }^{\circ} \mathrm{C}$, $1 \mathrm{~min}$ at $50{ }^{\circ} \mathrm{C}$, and $1 \mathrm{~min} 30 \mathrm{sec}$ at $72{ }^{\circ} \mathrm{C}$ for F-HN and F-HC; 1 min at $94{ }^{\circ} \mathrm{C}, 1 \mathrm{~min}$ at 54.5 ${ }^{\circ} \mathrm{C}$, and $40 \mathrm{sec}$ at $72{ }^{\circ} \mathrm{C}$ for F-HCc. Following completion of cycles, a final extension was 
carried out for an additional $7 \mathrm{~min}$ at $72{ }^{\circ} \mathrm{C}$. Amplified PCR products were purified by agarose gel elution kit (Intron Biotechnology, The Republic of Korea), and resultant PCR products were digested with restriction enzymes (Table 1) and subcloned into pGEX4T-1 vector using $\mathrm{T}_{4}$ ligase kit (Promega) for overnight at $16{ }^{\circ} \mathrm{C}$, so that the correct reading frame was incorporated along the thrombin cleavage site under the GST gene (representative constructs made from MacVector 10.0.2 (NC, USA) software containing F-LC and F-HN domains are shown in Fig. 2). Ligated samples were transformed into DH5 $\alpha$ by heat-shock $\left(42{ }^{\circ} \mathrm{C}\right.$ for $50 \mathrm{sec}$ ) method and positive clones with appropriate insert were screened out by use of LB agar plates containing $100 \mu \mathrm{g} / \mathrm{ml}$ ampicillin. Positive colonies containing the ligated constructs were transformed into BL21-RIL for the expression of type $F$ recombinant domains.

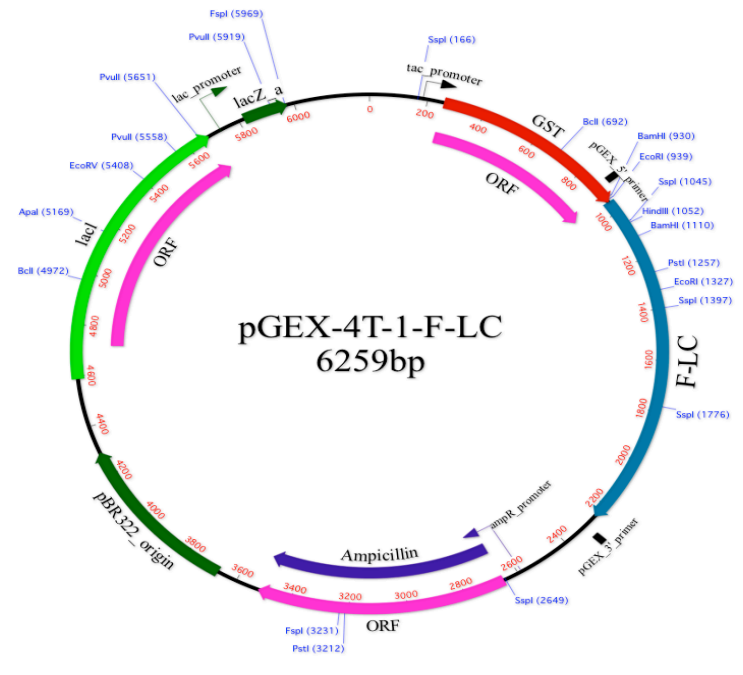

2 (a)

\section{Expression and purification of recombinant proteins}

To monitor the induction of recombinant domains in BL21-RIL, $2 \mathrm{ml}$ of transformant cultures were inoculated and grown in LB broth and induced at various time intervals using different concentrations of isopropyl $\beta$-D-1-thiogalactopyranoside (IPTG). In order to purify recombinant proteins, mass production was performed by inoculating 2 $\mathrm{ml}$ induced culture in 1 liter followed by centrifugation $(12,000 \mathrm{xg})$ at $4{ }^{\circ} \mathrm{C}$ for 20 min. Pellet was then resuspended in $10 \mathrm{ml}$ of $50 \mathrm{mM}$ phosphate buffered saline (PBS) and cells were then lysed by sonication, with 10 short bursts of $30 \mathrm{sec}$ followed by intervals of placing samples on ice for 1 min cooling.

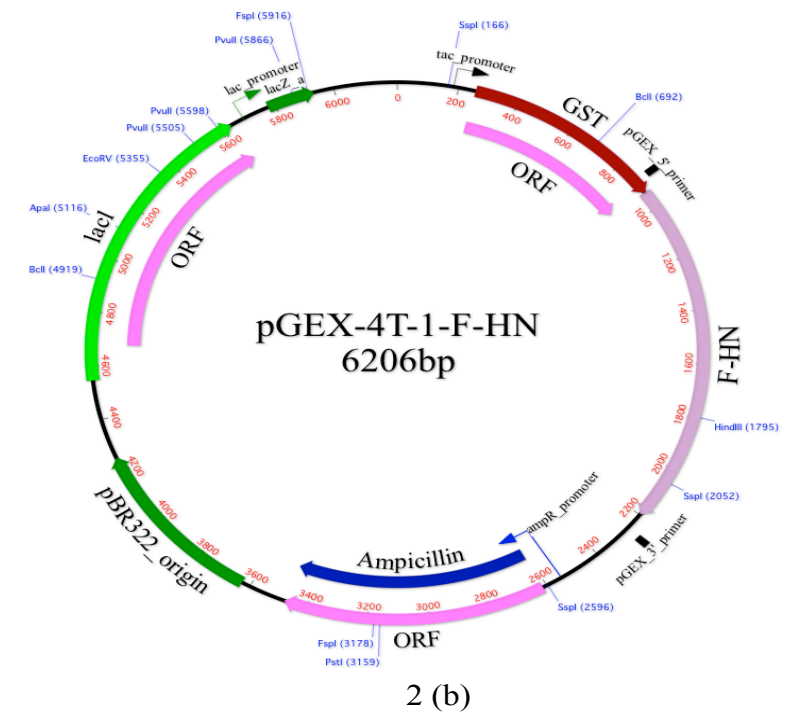

Fig.2: Schematic diagram of constructed plasmids generated by MacVector 10.0.2 software (Symantec Corporation). 
After centrifugation at $12,000 \mathrm{xg}$ for $30 \mathrm{~min}$, the pellet was resuspended in $10 \mathrm{ml}$ PBS overnight at $4{ }^{\circ} \mathrm{C}$ and supernatant was placed in a GST affinity chromatography column after column was initially washed multiple times with deionized water and PBS, followed by normalization with GST resin. The large scale of GST-fusion proteins was eluted by single step affinity chromatography (containing sepharose 4B beads). Fractions containing desired proteins were pooled and dialyzed for $2 \mathrm{~h}$ at $4{ }^{\circ} \mathrm{C}$ against PBS.

For thrombin protease treatment, resin bound GST-fusion proteins were cleaved with 20 units thrombin incubating for $30 \mathrm{~min}$ at $37^{\circ} \mathrm{C}$ followed by $15 \mathrm{~min}$ at room temp $\left(20-25^{\circ} \mathrm{C}\right)$ and final elution with $500 \mu \mathrm{l}$ PBS. The eluted proteins were further dialyzed to maintain salt concentrations and $\mathrm{pH}$. Protein concentrations were measured according to the Bradford method using a Bio-Rad model 550 microtiter plate reader. All proteins were labeled, aliquoted and stored at $-70{ }^{\circ} \mathrm{C}$ prior to use. Lastly, sodium dodecyl sulfate polyacrylamide gel electrophoresis (SDS-PAGE) was carried out on a $12 \%$ gel under reducing conditions in order to determine solubility of the eluted proteins.

\section{Production and analysis of polyclonal antibodies against $\mathrm{rF}-\mathrm{LC}$ and $\mathrm{rF}-\mathrm{HN}$}

For immunization, three female Balb/c mice (four weeks old having around 18-22 gram body weight) were immunized intraperitoneally with $10 \mu \mathrm{g}$ of antigen mixtures containing recombinant proteins $(25$ $\mu \mathrm{g}$ GST free F-LC or $25 \mu \mathrm{g}$ GST free F-HN) in PBS. Additionally, an equal volume of Freund's complete adjuvant was separately injected into each mouse. After two weeks lapse, the mice were immunized with the mixture containing $20 \mu \mathrm{g}$ of recombinant protein and equal volume of Freund's incomplete adjuvant. At the start of the fourth week following the initial immunization, the mice were finally boosted by intravenous injection of the recombinant proteins $(30 \mu \mathrm{g})$ without adjuvant. Three days following final boost, mice were then bled from the tail and tested by indirect ELISA.

\section{Preparation of monoclonal antibodies (hybridoma technology)}

Cell fusion and culture of hybridomas was carried out according to the protocol by Kohler et al. [24]. Briefly, cultures were incubated at $37{ }^{\circ} \mathrm{C}$ in an incubator with $5 \%$ $\mathrm{CO}_{2}$-in-air and $98 \%$ relative humidity. Four days following final boost, the mouse showing the highest antibody titer by ELISA was sacrificed by cervical dislocation and its spleen was removed aseptically. Spleen cells $\left(1 \times 10^{8}\right.$ viable cells) were mixed with SP2/0-

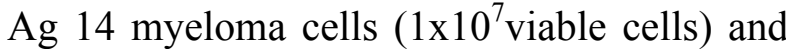


grown in Dulbecco's modified Eagle's medium (DMEM) supplemented with 10\% fetal bovine serum (FBS) (Hyclone). The addition of $50 \%$ polyethylene glycol 4000 (PEG) (Sigma Aldrich) allowed for the fusion of mixed cells; resulting in hybrid cells. Hybrid cells were screened by incubation in 96-well plates (Nunc) containing hypoxanthine-aminopterin-thymidine (HAT) selection medium in combination with mouse feeder cells for one week. Antibody production from hybrid cells was monitored through indirect ELISA; positive cells were expanded into 24-well plates (Nunc) containing hypoxanthine-thymidine (HT) media supplemented with dilute aminopterin according to the standard protocol by Harlow and Lane [25]. ELISA-positive hybridomas were selected and cloned twice via limiting dilution; one cell per well into $96-$ well plates supplemented with HT media and feeder cells. Finally, cloned cell lines were grown in DMEM supplemented with 10\% FBS and stored in liquid nitrogen.

\section{Indirect enzyme linked immunosorbent assay (ELISA)}

For the measurement of serum antibody titers, ELISA was performed as a standard protocol mentioned by Sigma Aldrich, with only minor modifications. Each well of 96 well plates (Nunc, Copenhagen, Denmark) was coated with antigen $(100 \mu \mathrm{l}$ containing $100 \mathrm{ng}$ of either GST free recombinant protein or $100 \mathrm{ng}$ BoNT/F) and incubated at $4{ }^{\circ} \mathrm{C}$ overnight. Each well was washed once with $200 \mu$ of PBS containing $0.05 \%$ Tween 20 (PBST) and blocking solution (100 $\mu 1$ 1\% skim milk) was added and incubated for $30 \mathrm{~min}$ at $37{ }^{\circ} \mathrm{C}$. Following two more washes, the serum (1: 1000 dilution) in PBS was added as the primary antibody. The plates were incubated at $37{ }^{\circ} \mathrm{C}$ for $90 \mathrm{~min}$, and then washed three times as described above. Goat anti-mouse IgG conjugated with alkaline phosphatase was added as the secondary antibody (diluted 1:2000 with PBS) and incubated for $2 \mathrm{~h}$. After incubation with $\operatorname{IgG}$, plates were washed four times prior to substrate treatment and visualization. Immobilized antigens were visualized with the $\mathrm{p}$-Nitrophenyl phosphate (disodium) in substrate buffer containing 9.7\% diethanolamine, and $1 \mathrm{mM} \mathrm{MgCl}_{2}$ and the resultant absorbance was measured at $415 \mathrm{~nm}$ with microplate reader (Model 550 Bio-Rad) for $5-10 \mathrm{~min}$ at $37^{\circ} \mathrm{C}$.

\section{Western blot analysis}

Western blot experimentation was adapted from previous methodology [26]. The protein samples were separated by SDS-PAGE and electroblotted for $\sim 70 \mathrm{~min}$ by using $230 \mathrm{~mA}$ current onto a nitrocellulose membrane (Schleicher and Schuell Inc., NH, USA). 
Subsequently, the membrane was blocked for nonspecific binding incubating with blocking solution for $1 \mathrm{~h}$ and then incubated with primary antibody overnight at room temp. The membrane was washed two times with PBST and incubated with alkaline phosphate conjugated goat anti-mouse $\operatorname{IgG}$ as a secondary antibody for $2 \mathrm{~h}$. After washing three more times with PBST, the membrane was color developed by using $10 \mathrm{ml}$ alkaline phosphate substrate solution, $50 \mu 1$ nitro blue tetrazolium chloride, and $50 \mu$ 5-bromo-4chloro-3-indolyl phosphate.

\section{Results and Discussion}

The cloning of both light and heavy chain domains using synthetic genes has been reported for various BoNTs [27-33]. However, there exist few studies on the cloning and expression of BoNT/F domains [34, 35]. Construction of recombinant plasmids containing pGEX-4T-1-F-LC, -HN, -HC, $\mathrm{HCc}$ was made for subsequent GST-tagged expression in E. coli. Initially, sequences of BoNT/F DNA domains were PCR amplified from genomic DNA of $C$. botulinum $\mathrm{F}$ str. Langeland and flanked by restriction sites (Table 1). Specifically, the amplified products were cloned into pGEX-4T-1 after digestion with respective restriction enzymes. Ligated constructs (for reference see schematic diagrams of constructed plasmids made by MacVector software 10.0.2, Fig. 2) were transformed into $\mathrm{DH} 5 \alpha$ for propagation and positive colonies were identified after screening on plates containing ampicillin. Subsequently the recombinant plasmids were digested with restriction enzymes (Table 1) and appropriate band sizes were identified for both pGEX-4T-1 (4.9 kb) and all individual fragment sizes (Fig. 3). For confirmation of domain homology incorporated into our vector, sequencing was performed. After sequence analysis, plasmid DNA of positive clones had $100 \%$ identity with native sequences (data not shown).

For protein expression, the four recombinant clones were transformed into E. coli BL21CodonPlus-RIL (strain used for protein expression with vectors driven by non-T7 promoters). The BL21-CodonPlus-RIL was chosen because of its capability to express rare codons which allows for the high-level expression of recombinants [36]. Thus, BL21CodonPlus-RIL was a compatible host strain for our pGEX-4T-1 plasmid systems (containing a tac promoter). All domains were expressed in the form of fusion proteins with GST localized at the N-terminal of the fusion protein, enabling the 

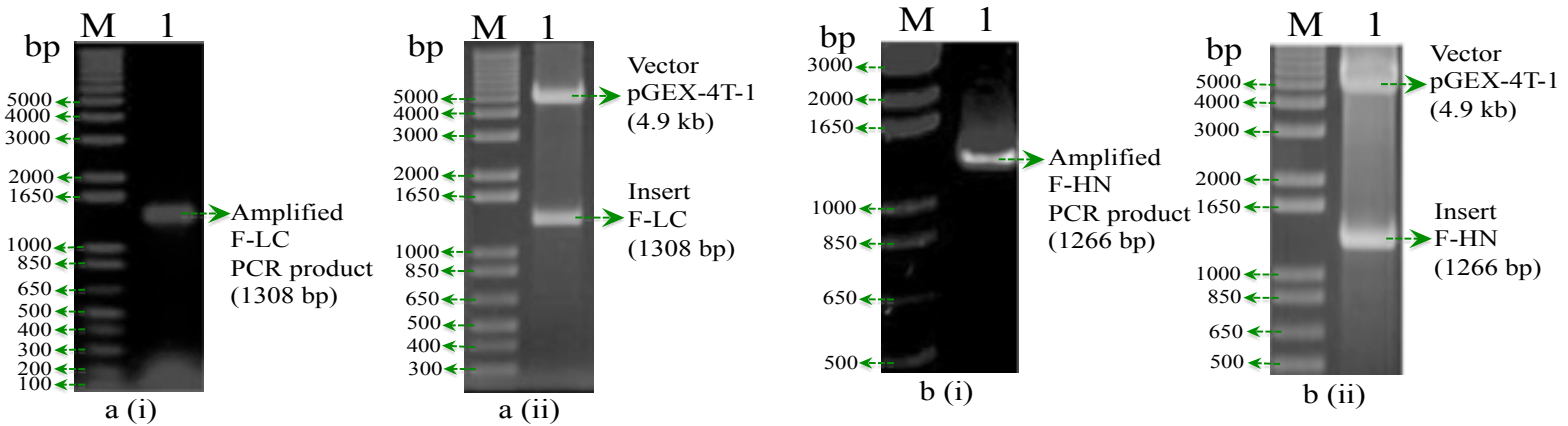

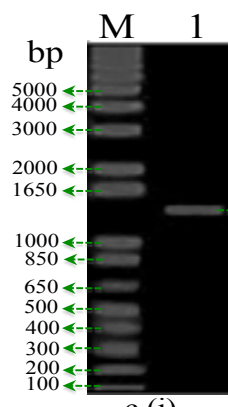

c (i)
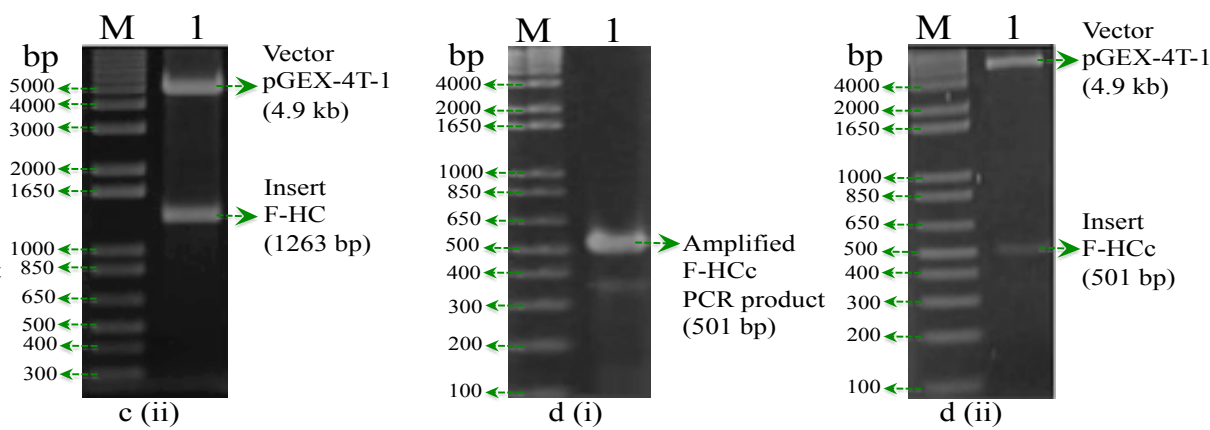

Fig.3: Agarose gel (1\%) electrophoresis of PCR product and restriction digested plasmid stained with ethidium bromide and visualized by UV

(i) Visible bands of amplified F-LC product (3a), F-HN (3b), F-HC (3c), and F-HCc (3d); (ii) Endonuclease restricted bands of purified pGEX4T-1-F-LC with SalI/NotI (3a), pGEX-4T-1-F-HN (3b), pGEX-4T-1-F-HC (3c), and pGEX-4T-1-F-HCc (3d) with BamI/XhoI.

M denotes DNA marker and Lane 1, DNA sample loaded.

ease of purification using GST affinity chromatography. Expression of clostridial proteins at $37{ }^{\circ} \mathrm{C}$ has been shown to increase protein degradation [37], thus we chose an optimal temperature range of $20-25^{\circ} \mathrm{C}$ for our expression studies. Conditions for expression of recombinant proteins were as follows: $7 \mathrm{~h}$ at $24{ }^{\circ} \mathrm{C}$ using $0.5 \mathrm{mM}$ IPTG concentration for GST-F-LC, $8 \mathrm{~h}$ at $22^{\circ} \mathrm{C}$ using $0.4 \mathrm{mM}$ IPTG concentration for GST-F-HN, $8 \mathrm{~h}$ at $20{ }^{\circ} \mathrm{C}$ using $0.25 \mathrm{mM}$ IPTG concentration for GST-F$\mathrm{HC}$, and $8 \mathrm{~h}$ at $20{ }^{\circ} \mathrm{C}$ using $0.10 \mathrm{mM}$ IPTG concentration for GST-F-HCc. GST-F-LC and
GST-F-HN induction was monitored by SDSPAGE (Fig. 4) and were found to be highly over-expressed in soluble form and purified at high concentrations.

Despite induction at low temperature and IPTG concentrations, GST-F-HC and GST-F-HCc were expressed in inclusion bodies. Change in expression vectors from pGEX-4T-1 to pET$32 \mathrm{a}(+)$ was then carried out in attempt to obtain soluble forms of GST-F-HC and GST-F-HCc. pET-32a $(+)$ was subsequently transformed into BL21-CodonPlus(DE3)-RIL host cells, that utilizes the T7 RNA polymerase promoter. 

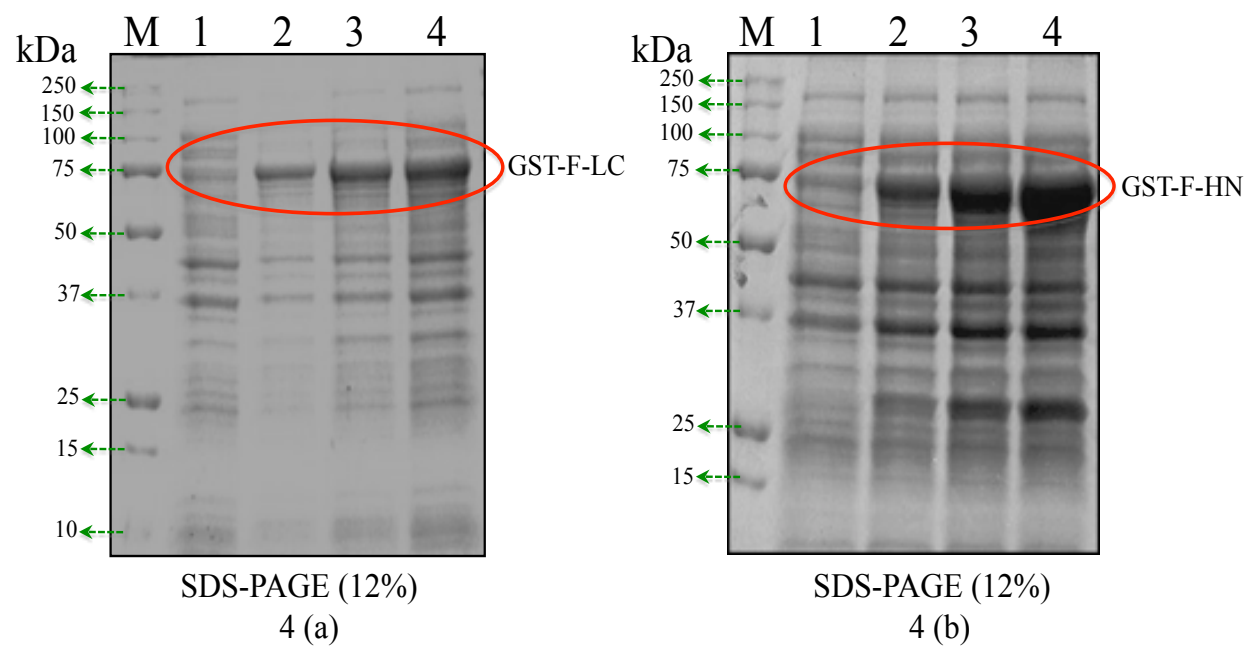

Fig.4: Induction and expression analysis of recombinant proteins

IPTG induction was carried out in a time dependent manner and SDS-PAGE (12\%) analysis of total lysate of E. coli BL21- (pGEX-4T-1-F-LC (a) and pGEX-4T-1-F-HN (b) with or without IPTG induction stained with Coomassie blue.

Lane M: protein marker (Bio-Rad); Lanes 1 - 4: (0, 2, 5, and $7 \mathrm{~h}$ for F-LC and 0, 2, 5, and $8 \mathrm{~h}$ for F-HN) after IPTG induction. Lanes 2 - 4 demonstrate expressed GST-F-LC a) and GST-F-HN (b) with treatment of IPTG.

$\mathrm{kDa}$, protein size expressed in kiloDalton.

Although both vectors contain thrombin cleavage sites and are ideal for production of soluble proteins, neither one was able to alter the formation of inclusion bodies. Proteinrefolding procedures were performed using reducing reagents including various molar concentrations of urea or guanidine $-\mathrm{HCl}$ to solubilize the inclusion bodies but attempts were unsuccessful. As a result, only LC and $\mathrm{HN}$ domains were used for protein analysis and collection of polyclonal serum from immunized mice. GST affinity chromatography was then carried out to collect GST tagged LC and HN. After GST affinity chromatography and cleavage with thrombin protease treatment, recombinant GST free F-LC and GST free F-HN were analyzed on SDS-PAGE to monitor expected protein bands. SDS-PAGE revealed the appropriate size of both recombinants; GST fused $75 \mathrm{kDa}$ and GST free $50 \mathrm{kDa}$ (Fig. 5). Final recombinant protein concentrations were determined to be $1.0 \mathrm{mg} / \mathrm{l}$. In order to analyze specificity of mice polyclonal sera against FLC and F-HN, mice were immunized intraperitoneally with antigens; GST free FLC and F-HN. To analyze the specificity of the polyclonal serums against F-LC and F$\mathrm{HN}$, mouse polyclonal serum was collected from the tail vain and tested by Western blotting and indirect ELISA (both of these techniques being highly valuable in the detection of candidate biomarkers). The mouse anti-F-LC polyclonal antibodies were found to specifically recognize F-LC and BoNT/F (Figs. 5a and 6a). Similarly, anti-F$\mathrm{HN}$ polyclonal antibodies demonstrated a 
strong affinity towards F-HN and native type $\mathrm{F}$ toxin (Figs. $5 \mathrm{~b}$ and $6 \mathrm{~b}$ ). However, neither anti-F-LC nor anti-F-HN polyclonal antibodies were able to detect the $\mathrm{HC}$ domain (Fig. 5), validating the specificity of the polyclonal serums towards their respective region of $\mathrm{BoNT} / \mathrm{F}$. The designated recombinant domains have native structure as holotoxin and it was not unexpected for them to produce anti-sera against native toxin $(\mathrm{BoNT} / \mathrm{F})$.
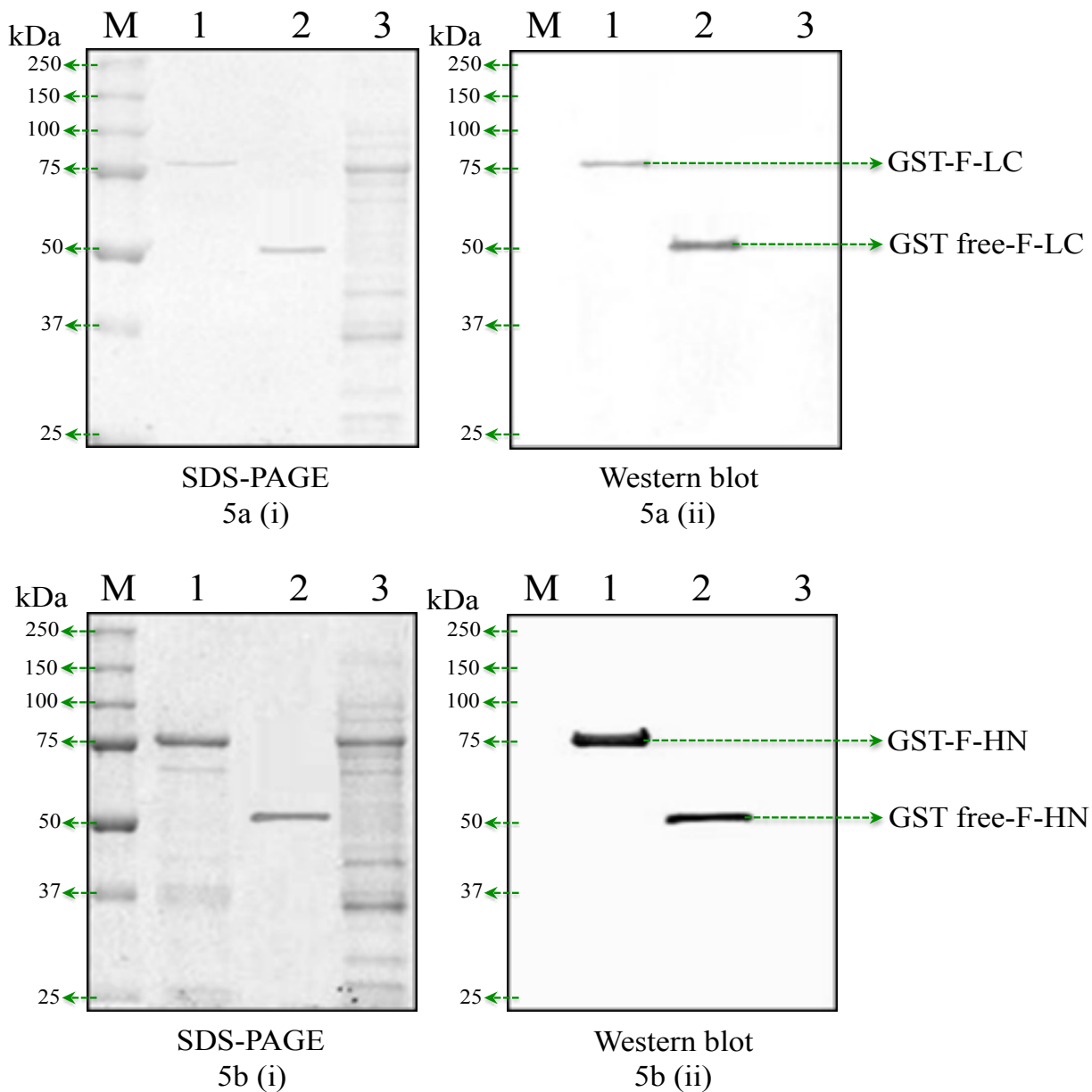

Fig.5: Purification and characterization of recombinant BoNT/F domain proteins

(i) SDS-PAGE of purified GST F-LC and GST free F-LC (a) Purified GST F-HN and GST free F-HN (b) by single step GST affinity chromatography separated on a $12 \%$ gel and visualized by Coomassie blue stain; (ii) Western blot analysis performed by raising anti-F-LC (a) and anti-F-HN (b) mouse polyclonal antibody.

Lane M: protein marker (Bio-Rad); Lane 1, GST-F-LC or HN; Lane 2, GST free-F-LC or HN; and Lane 3, unpurified GST-F-HC. 


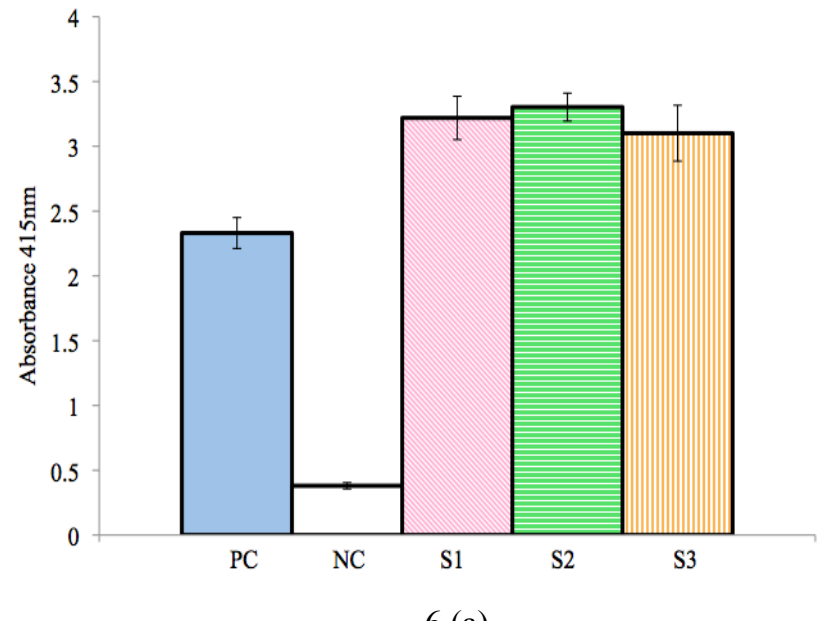

$6($ a)

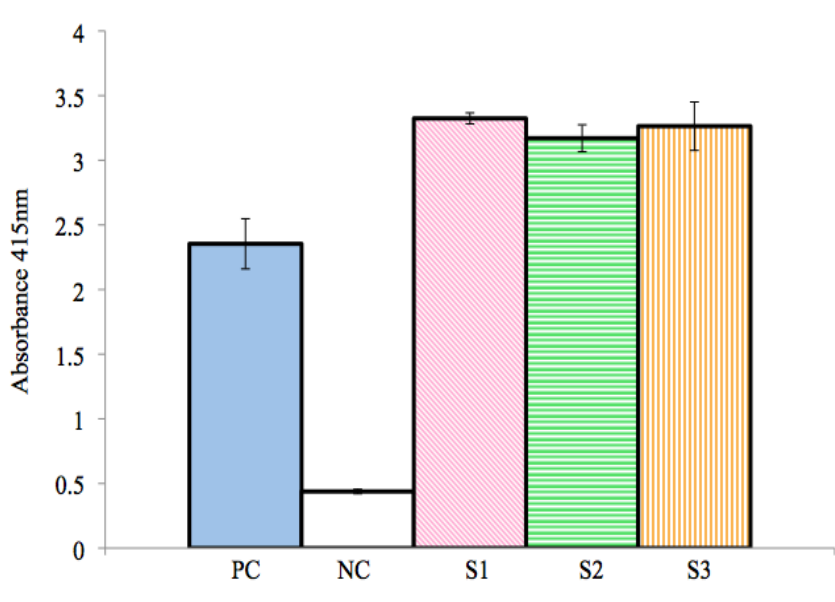

6 (b)

Fig.6:Immunoreactivity analysis by Indirect ELISA

Bar graph values represent interaction of anti F-LC (a) and anti-F-HN (b) mouse polyclonal serum antibody with: PC $=$ BoNT/F as a coating antigen; S. 1 - 3 = samples of GST free F-LC (a) and GST free F-HN (b) coating antigens respectively \& interaction of non-immunized mouse serum with: NC= GST free F-LC (a) and GST free F-HN (b) used as coating antigens respectively.

Mouse polyclonal serum was harvested from three different mice (from different batches) immunized with GST free F-LC or GST free F-HN. PC- positive control, NC- negative control. $\mathrm{n}=3$ wells, two-tailed students t-test, $\mathrm{S}$. 1 - 3 compared to NC, $\mathrm{p}<0.05$.

Attempts were unsuccessful in isolating a monoclonal antibody specific towards our constructed BoNT/F domains (data not shown). However, we have successfully isolated a mouse monoclonal antibody that demonstrates neutralizing activity against native BoNT/F toxin resulting from BoNT/F toxiod in vivo immunization and hybridoma technology [38].

\section{Conclusion}

This paper describes molecular and immunological studies on $C$. botulinum neurotoxin type F domains. Synthetic genes encoding BoNT/F partial fragments: catalytic domain (rF-LC), translocation domain ( $\mathrm{rF}-$ $\mathrm{HN})$, receptor binding domain $(\mathrm{rF}-\mathrm{HC})$ and quarter part of $\mathrm{HC}(\mathrm{rF}-\mathrm{HCc})$ were designed and cloned into E. coli. Additionally, expression, purification, and immunoreactivites were analyzed by Western blotting and indirect ELISA for LC and $\mathrm{HN}$ domains. The use of GST tagged recombinant protein technology was chosen in order to optimize detection and acquisition of high purity, stable, and soluble proteins through use of single step affinity chromatography. Although host strains, vector types, and induction conditions for expression were optimized to recover recombinant proteins in the soluble fraction, we were unable to purify $\mathrm{HC}$ and $\mathrm{HCc}$. Immunoreactivity was accessed through GST free F-LC and F-HN through in vivo immunization and polyclonal serum antibody collection, proceeded by Western blotting and indirect ELISA.

The anti-F-LC and anti-F-HN mouse 
polyclonal antibodies exhibited a strong affinity towards GST free and GST tagged FLC and F-HN respectively, while both recognized the native type $\mathrm{F}$ toxin. From this work, we conclude that purified BoNT/F LC and $\mathrm{HN}$ domains are capable of producing highly effective immunogens. Moreover, if future attempts prove fruitful in the isolation of monoclonal antibodies (that possess neutralizing activity), towards BoNT/F fragments, this may lead to more efficient protection against a high neurotoxin dose. Implications of this research could span across the development of therapeutic approaches, diagnostic detection systems, and vaccine candidacy for the protection and treatment of botulism as has been elucidated in previous work [34, 37, 39-42]. In summary, we have expressed both recombinant $\mathrm{LC}$ and $\mathrm{HN}$ domains of BoNT/F. The recombinant proteins are soluble; elicit an active immune response (polyclonal antibodies) in mice, making them ideal for investigators to process potential subunit vaccines towards BoNT/F.

\section{Acknowledgements}

All authors wish to acknowledge the financial support from Medy-Tox Inc. and for their help in the acquisition of $C$. botulinum $\mathrm{F}$ str. Langeland and BoNT/F (Wako Pure Chemicals Ind., Osaka, Japan). We would also like to express our gratitude to Jesus Andres Cuaron for his contributions on the drafting of this article.

\section{References}

1. McCroskey LM, Hatheway CL, Fenicia L, Pasolini B, Aureli P: Characterization of an organism that produces type $E$ botulinal toxin but which resembles $C$. butyricum from the feces of an infant with type $\mathbf{E}$ botulism. J Clin Microbiol 1986, 23(1):201-202.

2. McCroskey LM, Hatheway CL, Woodruff BA, Greenberg JA, Jurgenson P: Type $\mathbf{F}$ botulism due to neurotoxigenic $C$. baratii from an unknown source in an adult. $J$ Clin Microbiol 1991, 29(11):26182620.

3. Sakaguchi G: C. botulinum toxins. Pharmacol Ther 1982, 19(2):165194.

4. Simpson LL (Ed): Botulinum Neurotoxin and Tetanus Toxin. San Diego, CA: Academic Press; 1989.

5. Burgen AS, Dickens F, Zatman LJ: The action of botulinum toxin on the neuro-muscular junction. $J$ Physiol 1949, 109(1-2):10-24.

6. Atlas RM: Bioterrorism and biodefence research: changing the focus of microbiology. Nat Rev Microbiol 2003, 1(1):70-74.

7. Bossi P, Bricaire F: [Botulism toxin, bioterrorist weapon]. Presse Med 2003, 32(10):463-465. 
8. Moore A: The biochemistry of beauty. The science and pseudoscience of beautiful skin. $E M B O$ Rep 2002, 3(8):714-717.

9. Brin MF: Botulinum toxin: chemistry, pharmacology, toxicity, and immunology. Muscle Nerve Suppl 1997, 6:S146-168.

10. Dressler D: Electromyographic evaluation of cervical dystonia for planning of botulinum toxin therapy. Eur J Neurol 2000, 7(6):713-718.

11. Jankovic J: Botulinum toxin in movement disorders. Curr Opin Neurol 1994, 7(4):358-366.

12. Sugiyama H, Das Gupta R, Yang KH: Disulfide-toxicity relationship of botulinal toxin types $A$, $E$, and F. Proc Soc Exp Biol Med 1973, 143(3):589-591.

13. DasGupta BR, Sugiyama H: A common subunit structure in $C$. botulinum type $A, B$ and $E$ toxins. Biochem Biophys Res Commun 1972, 48(1):108-112.

14. Schmidt JJ, Stafford RG: Botulinum neurotoxin serotype $F$ : identification of substrate recognition requirements and development of inhibitors with low nanomolar affinity. Biochemistry 2005, 44(10):4067-4073.

15. Schiavo G, Rossetto O, Catsicas S, Polverino de Laureto P, DasGupta BR, Benfenati F, Montecucco C: Identification of the nerve terminal targets of botulinum neurotoxin serotypes A, D, and E. $J$ Biol Chem 1993, 268(32):23784-23787.

16. Chen S, Wan HY: Molecular mechanisms of substrate recognition and specificity of botulinum neurotoxin serotype $F$. Biochem J 2011, 433(2):277-284.

17. Agarwal R, Schmidt JJ, Stafford RG, Swaminathan S: Mode of VAMP substrate recognition and inhibition of $C$. botulinum neurotoxin F. Nat Struct Mol Biol 2009, 16(7):789-794.

18. Montecucco C, Schiavo G: Mechanism of action of tetanus and botulinum neurotoxins. Mol Microbiol 1994, 13(1):1-8.

19. Schiavo G, Matteoli M, Montecucco $\mathrm{C}$ : Neurotoxins affecting neuroexocytosis. Physiol Rev 2000, 80(2): 717-766.

20. Lacy DB, Tepp W, Cohen AC, DasGupta BR, Stevens RC: Crystal structure of botulinum neurotoxin type $A$ and implications for toxicity. Nat Struct Biol 1998, 5(10):898-902.

21. Montecucco C, Schiavo G, Gao Z, Bauerlein E, Boquet P, DasGupta BR: Interaction of botulinum and tetanus toxins with the lipid bilayer surface. Biochem $J$ 1988, 251(2):379-383.

22. Yu YZ, Sun ZW, Wang S, Yu WY: High-level expression of the Hcc domain of $C$. botulinum neurotoxin serotype $A$ in $E$. coli and its immunogenicity as an antigen. Sheng Wu Gong Cheng Xue Bao 2007, 23(5):812-817.

23. Moller V, Scheibel I: Preliminary report on the isolation of an apparently new type of $C$. botulinum. Acta Pathol Microbiol Scand 1960, 48:80. 
24. Kohler G, Howe SC, Milstein C: Fusion between immunoglobulinsecreting and nonsecreting myeloma cell lines. Eur J Immunol 1976, 6(4):292-295.

25. Harlow E, Lane D: Antibodies: A Laboratory Manual: Cold Spring Harbor Laboratory Press; 1988.

26. Towbin H, Staehelin T, Gordon J: Electrophoretic transfer of proteins from polyacrylamide gels to nitrocellulose sheets: procedure and some applications. Proc Natl Acad Sci US A 1979, 76(9):43504354.

27. Agarwal R, Eswaramoorthy $\mathrm{S}$, Kumaran D, Dunn JJ, Swaminathan $S$ : Cloning, high level expression, purification, and crystallization of the full length $C$. botulinum neurotoxin type $E$ light chain. Protein Expr Purif 2004, 34(1):95102.

28. Zhou Y, Singh BR: Cloning, highlevel expression, single-step purification, and binding activity of His6-tagged recombinant type $B$ botulinum neurotoxin heavy chain transmembrane and binding domain. Protein Expr Purif 2004, 34(1):8-16.

29. Sharma S, Zhou Y, Singh BR: Cloning, expression, and purification of C-terminal quarter of the heavy chain of botulinum neurotoxin type A. Protein Expr Purif 2006, 45(2):288-295.

30. Mansour AA, Mousavi SL, Rasooli I, Nazarian S, Amani J, Farhadi N: Cloning, high level expression and immunogenicity of 1163-1256 residues of $\mathrm{C}$-terminal heavy chain of $\boldsymbol{C}$. botulinum neurotoxin type $\mathbf{E}$. Biologicals 2010, 38(2):260-264.

31. Whelan SM, Elmore MJ, Bodsworth NJ, Brehm JK, Atkinson T, Minton NP: Molecular cloning of the $C$. botulinum structural gene encoding the type $B$ neurotoxin and determination of its entire nucleotide sequence. Appl Environ Microbiol 1992, 58(8):2345-2354.

32. Yang GH, Rhee SD, Jung HH, Jhee $\mathrm{OH}$, Yang $\mathrm{KH}$ : Cloning and characterization of the upstream region of $C$. botulinum type $B$ neurotoxin gene. Biochem Mol Biol Int 1998, 45(2):401-407.

33. Zhou Y, Paturi S, Lindo $P$, Shoesmith SM, Singh BR: Cloning, expression, purification, and characterization of biologically active recombinant hemagglutinin33, type A botulinum neurotoxin associated protein. Protein J 2007, 26(1):29-37.

34. Yu YZ, Li N, Wang RL, Zhu HQ, Wang S, Yu WY, Sun ZW: Evaluation of a recombinant $\mathrm{Hc}$ of $C$. botulinum neurotoxin serotype $F$ as an effective subunit vaccine. Clin Vaccine Immunol 2008, 15(12):1819-1823.

35. Agarwal R, Binz T, Swaminathan S: Structural analysis of botulinum neurotoxin serotype $F$ light chain: implications on substrate binding and inhibitor design. Biochemistry 2005, 44(35):11758-11765.

36. Zdanovsky AG, Zdanovskaia MV: Simple and efficient method for heterologous expression of clostridial proteins. Appl Environ Microbiol 2000, 66(8):3166-3173. 
37. Woodward LA, Arimitsu H, Hirst R, Oguma K: Expression of HC subunits from $C$. botulinum types $C$ and $D$ and their evaluation as candidate vaccine antigens in mice. Infect Immun 2003, 71(5):29412944.

38. Dulal S, Ban B, Kim KS, Yang GH, Jung $\mathrm{HH}$. : Neutralizing antibody specific to $C$. botulinum neurotoxin serotype F (BoNT/F). Abstracts of the 110th General Meeting of the American Society for Microbiology (American Society for Microbiology, San Diego , CA, 23rd-27th May) , $p$ 1102010.

39. Yang GH, Kim KS, Kim HW, Jeong ST, Huh GH, Kim JC, Jung HH: Isolation and characterization of a neutralizing antibody specific to internalization domain of $C$. botulinum neurotoxin type $B$. Toxicon 2004, 44(1):19-25.

40. Baldwin MR, Tepp WH, Przedpelski A, Pier CL, Bradshaw M, Johnson EA, Barbieri JT: Subunit vaccine against the seven serotypes of botulism. Infect Immun 2008, 76(3):1314-1318.

41. Webb RP, Smith TJ, Wright PM, Montgomery VA, Meagher MM, Smith LA: Protection with recombinant $C$. botulinum $\mathrm{C} 1$ and D binding domain subunit (Hc) vaccines against $C$ and $D$ neurotoxins. Vaccine 2007, 25(21):4273-4282.

42. Webb RP, Smith TJ, Wright P, Brown J, Smith LA: Production of catalytically inactive BoNT/A1 holoprotein and comparison with BoNT/A1 subunit vaccines against toxin subtypes A1, A2, and A3. Vaccine 2009, 27(33):4490-4497. 